\title{
El anticristo de F. Nietzche como propedéutica de la fe cristiana
}

\author{
Jordi Corominas, \\ Departamento de Filosofia, \\ Universidad Centroamericana "José Simeón Cañas", \\ San Salvador.
}

El cristianismo auténtico, el originario, será posible en todos los tiempos. No un creer, sino un hacer, sobre todo un no-hacer-muchas-cosas, sino un ser distinto...

F. Nietzsche

El Anticristo, maldición sobre el cristianismo, es la última obra de F. Nietzsche, escrita antes de que cayera en la demencia, en 1889. En principio parece una obra colérica, un ajuste de cuentas con la Iglesia y el cristianismo, Ilena de vituperios y desbordante de insultos y provocaciones ${ }^{1}$. Pero atrevámonos a leer la obra con todo el sobrecogimiento, el escalofrío y los mecanismos de defensa que nos suscite. Dejemos por un momento todos los juicios y todas las polémicas a favor o en contra de Nietzsche: las polémicas protestantes que han utilizado la obra contra los católicos (la Iglesia como anticristo); las polémicas de los católicos que han utilizado la obra contra los protestantes (el protestantismo como hemiplejia del cristianismo y de la razón); las polémicas de los ateos contra los cristianos (el cristianismo en su conjunto, como origen y máxima expresión de la inversión de los valores y del nihilismo); las controversias de los cristianos contra los ateos (el ateísmo de socialistas, comunistas, anarquistas, etc.,

1. Curiosamente, la misma hermana de Nietzsche podría scr una bucna acrecdora de todas las maldiciones que lanza F. Nietzsche en esta obra contra el cristianismo, pues su "defensa de los valores crisitanos" cs lo que la lleva a un antisemitismo militantc y a silenciar partes importantes del manuscrito de Nietzsche. Por suerte se ha podido rccupcrar la obra original, salvándola de la poda a la que la sometió su hermana Elisabeth. 
como expresión laica del cristianismo que denuncia Nietzsche); las controversias de los progresistas contra los conservadores (Nietzsche como filonazi) y de los conservadores contra los progresistas (Nietzsche como despreciador de los revolucionarios). Abandonemos la discusión sobre el grado y la naturaleza de los padecimientos psicológicos de Nietzsche, el contexto puritano, las relaciones familiares, sus vivencias sexuales. Dejemos por un momento en un segundo plano su biografía y su atormentada vida. Intentemos, en la medida de lo posible, no edulcorar ni suavizar a Nietzsche, respetando su singularidad. Leamos sin prevención El Anticristo y luego pongamos todos los paños de agua tibia y emplastes que haga falta y recuperemos todos los ríos de tinta que se quieran y que ha generado esta delirante obra.

\section{El cristianismo histórico como espíritu refinado de venganza}

Si evitamos caer en el juego de la provocación y el insulto, podemos apreciar en El Anticristo la condensación de todos los motivos de la obra nietzscheana. En primer lugar, el cristianismo aparece como la destilación más refinada del resentimiento, de la inversión de los valores que potencian una sana vitalidad, poder creativo y amor a la vida. Todas sus virtudes y deberes no tendrían otra razón de ser que el resquemor de quienes empezaron a creer en ellas para superar su debilidad e impotencia. Nietzsche pone el grito en el cielo contra todo regodeo enfermizo en la muerte, la decrepitud, el pesimismo y el celibato; contra todo considerar bueno lo que pone enfermo y malo lo que procede de la sobreabundancia, de la plenitud y del poder: “ Dios degenerado a ser la contradicción de la vida, en lugar de ser su transfiguración y su eterno sí!"2. Sobre todo Nietzsche no soporta el desprecio del cuerpo, la falta de higiene sensual, el rechazo de la alegría que proporcionan los sentidos, la casuística del pecado y los chismes como medio para combatir el aburrimiento 3 , y acaba considerando "la cruz como signo de reconocimiento para la más subterránea conjura habida nunca, contra la salud, la belleza, la buena constitución, la valentía, el espíritu, la bondad de alma, contra la vida misma"4.

En segundo lugar el cristianismo constituiría la victoria del nihilismo, de la nada, de un más allá de la tierra y de la vida humana. La compasión sería justamente la praxis del nihilismo5 porque, al contrario del amor, mantendría al débil en su debilidad y hasta acabaría congraciándose con su desgracia y conservando su miseria. La compasión cristiana persuadiría a entregarse a la nada, al "más allá", a Dios, a la vida verdadera, al nirvana o a todo lo que en general es

2. F. Nietzsche, El Anticristo, Madrid, 1981, párrafo 18.

3. Ibid., párrafo 21 .

4. Ibid., párrafo 62.

5. Ibid., párrafo 7.

Digitalizado por Biblioteca "P. Florentino Idoate, S.J."

Universidad Centroamericana José Simeón Cañas 
hostil a la vida ${ }^{6}$. Los teólogos, tanto protestantes como católicos, serían los principales abogados e infiltradores de la nada. Todo otro nihilismo arrancaría del cristiano.

En tercer lugar, el cristianismo encarnaría el espíritu metafísico por excelencia, el esfuerzo por crear trasmundos platónicos, aristotélicos o hegelianos para evadirse de la contingencia. El cristianismo sería fundamentalmente un platonismo para el pueblo. Nietzsche considera la fe, el amor y la esperanza como las tres grandes "listezas" cristianas para escapar de la finitud y del miedo a la vida. La fe como descrédito de la razón, del conocimiento y de la investigación, como argucia del poder sacerdotal: "Dios perdona a quien hace penitencia, dicho claramente a quien se somete al sacerdote" 7 . La esperanza como capacidad de entretener a los desgraciados y de mantenerlos en pie como sustituto de la felicidad acontecida en la realidad8. El amor como fuerza ilusoria, dulcificadora y empalagosa, que impide al hombre ver como son realmente las cosas?.

$\mathrm{Y}$ en cuarto lugar el cristianismo no sería más que un modo mezquino de actuar que va calculando alambicadamente la retribución de los mismos actos. Lo que en el fondo perseguiría la astucia cristiana es dar un sentido a la vida y ser retribuido por sus buenas acciones. El cristianismo sería en definitiva el gran invento de todos los seres sufrientes y resentidos para sostenerse en una esperanza que ninguna realidad pueda desmentir. Dios es quien asegura en última instancia la correspondencia de todas nuestras acciones con los resultados, ya sea en este mundo como cómputo final de la vida, ya en el otro. “¿Os irritáis conmigo porque enseño que no existe ni remunerador ni pagador? $\mathrm{Y}$ en verdad ni siquiera enseño que la virtud sea su propia recompensa"10. El noble, el aristócrata, el "sobrehombre" es justamente la metáfora empleada por Nietzsche para referirse a un hombre capaz de actos libres y gratuitos que no busca recompensa. "Frente al esquema de la ley y sus corrosivas consecuencias: resentimiento, negación de la vida, trasmundos, búsqueda de recompensas, Nietzsche quiere rescatar el carácter definitivo de nuestras obras"11.

El decidido rechazo del cristianismo en todas sus formas (protestantismo, catolicismo, ortodoxia etc.) hace que la simpatía y admiración de Nietzsche por

6. Ibid., párrafo 32 .

7. Ibid., párrafo 26 .

8. Ibid., párrafo 23.

9. Ibid., párrafo 23 .

10. F. Nietzsche, Asi habló Zaratustra, Alianza Editorial, 1975, p. 143. De esa crítica no escaparía el liberalismo burgués que hallaría en la ascćtica del ahorro, o en el gasto y el éxito económico una compensación social de sus actos, ni el socialismo que buscaría en la tierra la compensación y la retribución de los que sufren.

11. Aída Estella Sánchez, La crítica de Nietzsche al cristianismo: crítica al esquema de la ley, Tcsis de liccnciatura, UCA, San Salvador, 1995, p. 49. 
Jesús sea mucho más sorprendente. Pero la sorpresa va en aumento si delineamos la figura de Jesús que nos presenta Nietzsche en El Anticristo. ¿No podría ser que nos acercara mucho mas al núcleo de la fe cristiana que muchas de las aproximaciones teológicas a la figura de Jesús? No se trata de hacer trampa y de bautizar a Nietzsche. Decididamente no es cristiano, ¿pero no podría ser que estuviera mucho más cerca de la verdad cristiana que muchos cristianos? ¿No podría ser que él, conocido por su combate al cristianismo, fuera también uno de los filósofos más próximos a la verdad cristiana?

\section{Jesús como antítesis del cristianismo}

En primer lugar, la vida de Jesús es para Nietzsche la antítesis del cristianismo histórico. El es propiamente el único cristiano que ha existido. "El 'evangelio' murió en la cruz. Lo que a partir de ese instante se llama 'evangelio' era ya la antítesis de lo que él había vivido: una mala nueva, un disangelio. Es falso hasta el sinsentido ver en una 'fe', en la fe, por ejemplo, en la redención por Cristo, el signo distintivo del cristiano: sólo la práctica cristiana, una vida tal como la vivió el que murió en la cruz, es cristiana. [...] Todavía hoy esa vida es posible, para ciertos hombres es incluso necesaria: el cristianismo auténtico, el originario, será posible en todos los tiempos. [...] No un creer, sino un hacer, sobre todo un no-hacer-muchas-cosas, un ser distinto [...] Reducir el ser-cristiano, la cristiandad, a un tener-algo-por-verdadero, a una mera fenomenalidad de conciencia, significa negar la cristiandad. De hecho, no ha habido en absoluto cristianos"'12. Jesús es en primer lugar el incrédulo, el impío y el ateo respecto a cualquier tipo de resentimiento, particularmente respecto al resentimiento de la Iglesia, de los sacerdotes y de los teólogos. El mayor rebelde que haya existido contra "los buenos y los justos", contra los "santos de Israel", contra las buenas clases medias. "Ese anarquista santo, que incitaba al bajo pueblo, a los excluidos y pecadores, a contradecir el orden dominante, con un lenguaje que, en el caso que hubiera de fiarse de los evangelios, todavía hoy conduciría a Siberia, era un criminal político, hasta el punto en que eran posibles precisamente los criminales políticos, en una sociedad absurdamente apolítica. Eso fue lo que le llevó a la cruz: la prueba de esto es la inscripción puesta en ella. Murió por su culpa, falta toda razón para aseverar, aunque se haya aseverado con tanta frecuencia, que murió por la culpa de otros"13. "Se podría llamar a Jesús un espíritu libre, ninguna cosa fija le importa: la palabra mata, todo lo que está fijo mata. La experiencia de vida, única que él conoce, se opone en él a toda especie de palabra, fórmula, ley, fe, dogma" 14 .

12. F. Nietzsche, El Anticristo, párrafo 39.

13. Ibid., párrafo 56 .

14. Ibid., párrafo 33 .

Digitalizado por Biblioteca "P. Florentino Idoate, S.J."

Universidad Centroamericana José Simeón Cañas 
En segundo lugar, la buena nueva, el reino de Dios que proclama Jesús, es lo contrario de todo trasmundo. El Reino de Dios es la vida verdadera, la vida eterna encontrada aquí y ahora: "No se la promete, está ahí, está dentro de vosotros: como vida en el amor, en el amor sin sustracción, ni exclusión, sin distancia"15. La buena nueva consiste cabalmente en que ya no hay antítesis; el reino de los cielos pertenece a los niños. "La fe de Jesús no se encoleriza, no censura, no se defiende: no lleva la espada [...]. No da pruebas de sí misma, ni con milagros, ni con premios y promesas, y menos aún con la Escritura: ella misma es en todo instante su milagro, su premio, su prueba, su reino de Dios"16.

En tercer lugar contra toda voluntad de nada, contra toda contraposición entre eternidad y caducidad y toda asunción metafísica del Dios crucificado Nietzsche percibe la novedad del Dios cristiano. "Todo hombre es hijo de Dios - Jesús no reclama nada para sí solo- en cuanto hijo de Dios todo hombre es idéntico a otro. Esta es la novedad cristiana: que Jesús es igual a Dios. Los judíos no pueden entenderlo, se resisten a que alguien pueda ser llamado igual a Dios. La filiación divina es atribuida en el Antiguo Testamento a varias personas, pero ninguna pretende ser igual a Dios"17.

Y en cuarto lugar Nietzsche considera que Jesús es ajeno a la preocupación por el fruto y la retribución de las acciones. "En la psicología entera del evangelio falta el concepto culpa y castigo; asimismo, el concepto premio. El 'pecado', cualquier relación distanciada entre Dios y el hombre, se halla eliminado, justo eso es la 'buena nueva'. La bienaventuranza no es prometida, no es vinculada a unas condiciones: ella es la única realidad —el resto es signo para hablar de ella. [...] La consecuencia de semejante estado se proyecta en una nueva prácti$\mathrm{ca}$, la práctica propiamente evangélica. No es una ' $\mathrm{fe}$ ' lo que distingue al cristiano: el cristiano obra, se distingue por un obrar diferente. [...] El no establece ninguna diferencia entre extranjeros y nativos, judíos y no judíos"18. "La vida del Redentor no fue otra cosa que esa práctica, tampoco su muerte fue otra cosa... El ya no necesitaba, para su trato con Dios, fórmulas ni ritos, ni siquiera la oración. Ha roto con la entera doctrina judía de penitencia y reconciliación; sabe que únicamente con la práctica de la vida es como uno se siente 'divino', 'bienaventurado', 'evangélico', hijo de Dios en todo tiempo. Ni la 'penitencia' ni la 'oración en demanda de perdón' son caminos que conducen a Dios: sólo la práctica evangélica conduce a él, ella precisamente es 'Dios'. Lo que con el evangelio quedó eliminado fue el judaísmo de los conceptos 'pecado', 'remisión

15. Ibid., párrafo 32.

16. Ibid., párrafo 32 .

17. Ibid., párrafo 29 . Véase nota 65 .

18. Ibid., párrafo 33. 
de los pecados', 'fe', 'redención por la fe'. La entera doctrina eclesiástica judía quedó negada en la 'buena nueva'" 19 .

“Este 'buen mensajero' murió tal como vivió, tal como enseñó, no para 'redimir a los hombres', sino para mostrar cómo se ha de vivir. Lo que él legó a la humanidad es la práctica: su comportamiento ante los jueces, ante los sayones, ante los acusadores y ante toda especie de calumnia y burla, - su comportamiento en la cruz. [...] Las palabras dichas al ladrón en la cruz contienen el evangelio entero: 'Este ha sido en verdad un hombre divino, un 'hijo de Dios', dice el ladrón. 'Si tú sientes eso- responde el Redentor "entonces estás en el paraíso, entonces también tú eres un hijo de Dios...' No defenderse, no encolerizarse, no hacer responsable a nadie... Por el contrario, no oponer resistencia ni siquiera al malvado, amarlo..."20. Para Nietzsche la muerte de Jesús en la cruz es la máxima victoria contra el mundo del resentimiento, del nihilismo, de la invención de trasmundos y del afán de retribución. Su muerte en cruz no puede entenderse como un sacrificio expiatorio. Al contrario, en realidad lo que Jesús nos ha mostrado es "el amor como única posibilidad de vida"21.

\section{Jesús como idiota}

Como si se avergonzara de tamaños elogios Nietzsche acaba vertiendo su cuota de invectivas a Jesús, pero aún éstas son más interesantes de lo que se podría desprender de una lectura rápida. Creo que incluso E. Fink pasa demasiado por alto los aspectos positivos que resalta Nietzsche en Jesús 22 . Cuando E. Fink alude al enfrentamiento nietzscheano entre Dionisos y el Crucificado piensa más en una dicotomía metafísica que en un drama o conflicto religioso que esté viviendo Nietzsche. Del mismo modo cuando Nietzsche nombra al Crucificado y describe la persona de Jesús lo asocia con Sócrates y Platón. E. Fink no aprecia en ningún caso la proximidad de la descripción que realiza Nietzsche de Jesús con la de Dostoievski y la sorprendente valoración de Jesús en medio de una obra en la que Nietzsche pone todo su empeño en hostigar al cristianismo. Ciertamente Nietzsche termina por considerar a Jesús como el más interesante decadente y como idiota, pero sin la carga de odio y de asco usuales con los cristianos. No creo, como han afirmado algunos teólogos 23 , que sea aquí donde haya que establecer el punto de divergencia entre la aproximación nietzscheana y la aproximación cristiana a Jesús. El término idiota e idiotismo que utiliza Nietzsche referido a Jesús en El Anticristo ha sido casi siempre malentendido

19. Ibid., párrafo 33 .

20. Ibid., párrafo 35 .

21. Ibid., párrafo 30 .

22. E. Fink, La filosofía de Nictzsche, Alianza Editorial, 1969, p. 194 ss.

23. Eusebi Colomer, "Nietzsche y el cristianismo" El pensamiento alemán de Kant a Heidegger, tomo III, Ed. Hcrder, Barcelona, 1990, p. 328. 
porque la hermana de Nietzsche silenció las lecturas que realizó Nietzsche de Dostoievski por un afán de defender su originalidad creadora. El propio Hans Küng cree ver una curiosa coincidencia entre el calificativo de Jesús como idiota y El Idiota de Dostoievski24, pero no tiene nada de curiosa esta coincidencia porque Nietzsche leyó minuciosamente a Dostoievski. Idiota no tiene en cualquier caso el sentido vulgar de imbécil o corto de alcances, sino de cándido o de inocente, de estúpido por exceso de bondad.

Para Nietzsche Jesús es un idiota en el sentido dostoievskiano. El idiota de Dostoievski, el príncipe Mishkin, es bueno porque ha vivido aislado del mundo "un mundo no tocado por ninguna especie de realidad"25. El príncipe Mishkin es descrito por Dostoievski como un hombre verdaderamente cristiano y de gran belleza moral, pero su bondad resulta de su epilepsia y de su alejamiento del mundo. "Justo el negar es lo totalmente imposible para él"26. El reino de Dios sería un estado psicológico y a Jesús al faltarle el nervio de la fuerza y de la pasión y al poseer una especie de exclusión instintiva de toda aversión y conflicto no dejaría de ser un personaje extemporáneo y ridículo. Nietzsche ve a Jesús exactamente como el Idiota de Dostoievski. El príncipe Mishkin, último de su estirpe y epiléptico, vive durante su juventud en las montañas de Suiza, donde es curado por un médico de su proceso de enajenación. La belleza que este príncipe recuerda de las montañas es desbancada definitivamente como puente a lo divino tan pronto como establece relación con otros seres humanos. Los argumentos estéticos de la metafísica quedan anulados ante la argumentación del enfermo que desea suicidarse y descansar para siempre de sus sufrimientos 27 : "Qué me importan a mi vuestra naturaleza, vuestro parque, vuestras salidas y puestas de sol, vuestro cielo azul y vuestras caras de satisfacción"28. Hippolite, tísico condenado a una muerte prematura, devuelve su billete de entrada a este festín de la naturaleza suicidándose. Y el príncipe Mishkin deja de ver en la belleza cósmica la transparencia de lo divino.

Ante esta tumba que es el mundo para Hippolite el príncipe Mishkin no tiene argumentos. Sólo el abrazo y las lágrimas. ¿No es este abrazo envuelto en lágrimas a la rebelión del enfermo Hippolite, el alma atea, rebelión atea que el príncipe defiende frente a él y a los demás, la única respuesta cristiana posible? También Alexis en Los hermanos Karamazov, la otra gran alma cristiana, defenderá la proclama rebelde de su hermano ateo Iván de “El gran inquisidor” contra

24. H. Küng, ¿Existe Dios?, Ed. Cristiandad, Madrid, 1979, p. 555.

25. F. Nietzsche, El Anticristo, párrafo 29.

26. Ibid., párrafo 32 .

27. Es sin duda impresionante y finísima la lectura teológica que realiza de El Idiota, Urs Von Balthasar, Gloria, una estética teológica, Ed. Encuentro, Madrid, 1988, Vol. 5, p. 181.

28. F. Dostoievski, Obras completas, ed. Aguilar, Madrid, 1972, vol. II , p. 811. 
la Iglesia solidarizándose con él. ¿No es este amor el que sorprende a Nietzsche y cuya sorpresa no logra evitar que se filtre entre sus ácidas palabras? ¿No radica toda la esencia del cristianismo en comprender y vivir el amor en este grado de profundidad como comunión con los infiernos de los otros sin intención de diferencia? ¿Quien osa hacer girar su propia vida en torno a este amor en cierto modo ajeno a toda filosofía, teología y cultura, no se expone al ridículo? "El príncipe es enteramente un niño"29. ¿Trasciende ese amor la génesis psicológica que haya podido tener?

Mishkin no perdona porque comprende sino porque ama. El perdón permanente de Mishkin se vuelve ridículo e idiota: " $j S a b e s$ que te engaña y sigues tan confiado! ¡Sólo faltaba eso! Por lo demás, no podía esperarse otra cosa de ti”30. La ridiculez del príncipe llega a su clímax cuando el príncipe la reconoce: "Sepan ustedes que, a mi modo de ver, ser ridículo puede, en ocasiones, representar algo bueno y hasta ser lo mejor: más pronto nos podemos perdonar unos a otros y más fácilmente reconciliarnos"31. El idiota da dinero a bribones, saca de la cárcel por deudas al viejo mentiroso Ivilquin, presta dinero a quien le ha difamado y comete las más inconcebibles locuras de todo género. Y vive estos consejos evangélicos de manera totalmente inconsciente, sin ninguna intención o intuición de hacer algo que suene a perfección; al contrario, él escucha con aprobación a todos los que le hacen ver su estupidez y que incluso lo acusan, "Sí, sí, tiene usted razón, dijo el príncipe con un pesar espantoso... ay de mi, siento que soy culpable de todo esto" 32 .

Urs Von Balthasar ve en otro idiota, Don Quijote, el santo patrón de la acción católica: "más todavía: es un trozo de dogmática descuidado por los teólogos católicos y que sólo en católico puede percibirse con humor, mientras que Lutero trató de expresarlo trágicamente en su dialéctica de los contradictorios de la sola fides y del hombre a la vez justo y pecador"33. La necedad y la memez de Don Quijote consiste en el intento de suprimir el abismo entre la idealidad de la gracia y la realidad humana mediante la "realidad" de sus acciones. El fracaso perpetuo de éstas, cómicamente visible a todo el mundo, no hacen mas que mostrar el abismo. Don Quijote echa en cara a Sancho que sea un mal cristiano "porque nunca olvidas la injuria que una vez te han hecho; pues sábete que es de pechos nobles y generosos no hacer casos de niñerías"34. Su misión como cristiano es "favorecer a los necesitados de favor y acudir a los

29. Ibid., vol. I, p. 559.

30. Ibid., vol. I, p. 742.

31. Ibid., vol. II, p. 912

32. Ibid., vol. II, p. 993

33. Urs Von Balthasar, "Ccrvantes, la ridiculcz y la gracia", Gloria, una estética teológica, Ed. Encuentro, 1988, Madrid, , Vol. 5, p. 161 ss.

34. M. Cervantes Don Quijote de la Mancha, Cupsa Editorial, p. 121. 
menesterosos"35 y "tropezando aquí, cayendo allí, despeñándome acá y levantándome acullá..., socorriendo viudas, amparando doncellas y favoreciendo casadas, huérfanos y pupilos"36. "A los caballeros andantes no les toca ni atañe averiguar si los afligidos, encadenados y opresos que encuentren por los caminos, van de aquella manera o están en aquella angustia por sus culpas o por sus gracias; sólo les toca ayudarles como menesterosos"37. El resultado de todo esto es que las situaciones van normalmente a peor y cuando entra en juego Don Quijote no hace más que mover a risa y caer en el ridículo. La comicidad del Quijote es la comicidad y el ridículo cristiano: "acometer a cada paso, modestamente, lo imposible"38. "En resumen, Don Quijote es tanto mejor cristiano cuanto que subjetivamente no tuvo pretensiones de santidad, y en cuanto que objetivamente sus ridículas empresas jamás podrán en ningún momento y desde ningún punto de vista contarse entre las empresas de Dios. Desde luego que en cuanto cristiano quiere el bien y nada más que el bien y, sin .embargo, debe reconocer, partiendo de este mundo, que toda su caballería cristiana no es mas que necedad... Precisamente así su existencia es un monumento perenne de existencia cristiana y un reverbero de la gloria de Dios"39.

Ciertamente, como ha destacado Aída Sánchez 40 hay una gran ambigüedad en la aproximación de Nietzsche a Jesús. En algunos fragmentos de su obra aparece una gran admiración por su figura, en otros aparece manteniendo una dependencia enfermiza de los otros y una especie de debilidad e inconsistencia interna: "En definitiva podemos decir que Nietzsche, por una parte, se siente atraído por la figura de Jesús. Se trata de una acción que ya no pretende premios, recompensas, milagros para demostrar su valor, sino que ella misma es su propia prueba. En Jesús se supera ese afán enfermizo y morboso de querer fundamentar la acción. Y precisamente por esta superación es que Jesús se muestra libre de todo resentimiento. Pero, por otra parte, Nietzsche ve en Jesús a ese personaje apacible, manso, bueno, que lleva el 'reino de los cielos' en su corazón, sin asidero en la realidad de las cosas, de la sociedad, de la historia y sus conflictos" 41 .

\section{El cristianismo como un judaísmo de confesión más libre}

Nietzsche considera que un tipo como Jesús tenía que ser desfigurado necesariamente por el mundo raro y enfermo en el que los evangelios nos introdu-

35. Ibid., II 27, 791.

36. Ibid., II 16, 690 .

37. Ibid., I 30, 325.

38. Urs Von Balthasar, op. cit, p. 168.

39. Ibid., p. 171.

40. Aída Estella Sánchez, La crítica de Nietzsche al cristianismo: crítica al esquema de la ley, p. 54 ss.

41. Ibid., pp. 57-58. 
cen. El predicador de la montaña, el mar y los prados es hecho preso por Pablo, teólogo litigante, colérico y maliciosamente sutil42. La Iglesia, ante el mensaje liberador y la praxis libre de Jesús, lo que hace es infiltrarla con el resentimiento metafísico, la voluntad de nada, la creación de trasmundos y la doctrina del premio y del castigo. Con ello, todo queda corrompido "hacer milagros, hacer profecías, expulsar demonios, todo esto es nada ante la acción de Jesús"43. Jesús, el alegre mensajero, es convertido por Pablo y la primitiva Iglesia en la figura repulsiva del redentor. Nietzsche considera que el cristianismo, como realidad histórica, no debe ser confundido con aquella raíz cuyo nombre recuerda, pues las demás raíces de las que ha crecido son mucho más poderosas que las de Jesús: "Es un abuso sin par amparar con aquel santo nombre instituciones de decadencia como las que se designan con las expresiones de 'Iglesia cristiana', 'fe cristiana' y 'vida cristiana'. ¿Qué es lo que negó Cristo?, todo lo que hoy se llama cristiano"44. "Que la humanidad esté postrada de rodillas ante la antítesis de lo que fue el origen, el sentido, el derecho del evangelio, que haya canonizado en el concepto 'Iglesia' justo aquello que el 'buen mensajero' sentía por debajo de sí, por detrás de sí. En vano se buscará una forma mayor de ironía histórico-universal" 45 .

Nietzsche adivina en el trastorno que produjo la muerte de Jesús la reaparición del resentimiento: "El sentimiento trastornado y, en lo más hondo, ofendido, el recelo de que acaso tal muerte fuera la refutación de su causa, el horrendo signo de interrogación '¿por qué precisamente así?' ése es un estado que se comprende muy bien. Aquí todo tenía que ser necesario, poseer un sentido, una razón, una suprema razón"46. Los discípulos "no entendieron precisamente lo principal, lo ejemplar en ese modo de morir, la libertad, la superioridad sobre todo sentimiento de ressentiment: ¡Signo de cuán poco de él llegaron a entender! En sí, Jesús no pudo querer con su muerte otra cosa que dar públicamente la prueba más fuerte, la demostración de su doctrina... Pero sus discípulos estaban lejos de perdonar esa muerte, lo cual habría sido evangélico en el sentido más alto; y menos aún de ofrecerse a una muerte idéntica, con una suave y afable calma de corazón... Fue justo el sentimiento menos evangélico de todos, la venganza, el que de nuevo se impuso" 47 .

"El evangelio había sido, sin embargo, precisamente, el estar-ahí, el estarcumplido ese 'reino', la realidad de ese 'reino'. Justo tal muerte era precisamente ese 'reino de Dios'" 48 ... Y a partir del resentimiento se reelabora una religión

42. F. Nictzsche, El Anticristo, párrafo 31.

43. Ibid., nota 78 reelaboración de Nietzsche.

44. Ibid., párrafo 36 .

45. Ibid., párrafo 36 .

46. Ibid., párrafo 40 .

47. Ibid., párrafo 40.

48. Ibid., párrafo 40 .

Digitalizado por Biblioteca "P. Florentino Idoate, S.J."

Universidad Centroamericana José Simeón Cañas 
sacrificial más: "Dios entregó a su Hijo para remisión de los pecados, como víctima. ¡Cómo se acabó de un solo golpe con el evangelio! ¡El sacrificio reparador, y en su forma mas repugnante, más bárbara, el sacrificio del inocente por los pecados de los culpables! ¡Qué horrendo paganismo! Jesús había suprimido en efecto el concepto de culpa- negó todo abismo entre Dios y el hombre, vivió esa unidad de Dios v hombre como su 'buena nueva'. ¡Y no como privilegio! A partir de ahora en el tipo del redentor ingresan sucesivamente: la doctrina del juicio y del retorno, la doctrina de la muerte como muerte-sacrificio, la doctrina de la resurrección, con la cual queda escamoteado el concepto entero de 'bienaventuranza', realidad entera y única del evangelio, ¡en favor de un estado después de la muerte!"49. "Vivir de tal modo que ya no tenga sentido vivir, eso es lo que ahora se convierte en el 'sentido"" 50.

La santidad de la vida, tal como Jesús la vivió, es convertida en una especie de santidad artificiosa, en una especie de santurronería que, en lugar de divulgar el evangelio, se predica a sí misma: “" ¡No juzguéis!' dicen, pero ellos mandan al infierno a todo lo que los estorba. Al hacer que Dios juzgue, son ellos mismos los que juzgan; al glorificar a Dios se glorifican a sí mismos; al exigir precisamente las virtudes de que ellos son capaces -más aún, que ellos necesitan para permanecer encumbrados-, aparentan grandiosamente pelear por la virtud, luchar por el dominio de la virtud. 'Nosotros vivimos, nosotros morimos, nosotros nos sacrificamos por el bien'. [...] Esta ha sido la especie más funesta de delirio de grandeza habido hasta ahora en la tierra: pequeños engendros de santurrones y mentirosos comenzaron a reivindicar para sí los conceptos 'Dios', 'verdad', 'luz', 'espíritu', 'amor', 'sabiduría', 'vida', como sinónimos de ellos mismos. [...] El cristiano es sólo un judío de confesión más libre"51.

K. Jaspers sostiene que la crítica de Nietzsche al cristianismo es la que sólo puede ser acometida por un cristiano auténtico52. A mi modo de ver hacer de Nietzsche un cristiano es no sólo una falta de consideración y de respeto con alguien que se debatió toda su vida contra el crucificado, sino que impide reconocer lo propio de la fe cristiana y lo propio de la fe dionisíaca53 de Nietszche. Nietzsche, por lo que puede desprenderse de sus textos, jamás llegó a experimentar ninguna confianza en la gracia absolutoria del Dios cristiano. Ahora bien, en otro sentido, K. Jaspers podría tener razón, y es que el cristianismo auténtico se muestra más diáfanamente que en cualquier otra filosofía en la

49. Ibid., párrafo 41 .

50. Ibid., párrafo 43.

51. Ibid., párrafo 45 .

52. Nietzsche et le christianisme, París, 1949, p. 17.

53. Dionisos es el nombre de la realidad finita divinizada, la santidad del ser mismo. Para una intcrcsantc y polćmica aproximación a la conccpción religiosa dc Nietzsche puede verse V. Massuh, Nietzsche y el fin de la religión, 1976. 
crítica de Nietzsche. Es lo que intentaremos mostrar siguiendo la lectura del Anticristo que han realizado algunos teólogos.

\section{E. Jüngel: El anticristo como recaída en la metafísica}

Jüngel va a seguir de algún modo, la crítica a la metafísica de Heidegger, en la cual Nietzsche es precisamente el último metafísico en el sentido de que en él culminan todas las posibilidades metafísicas y el platonismo llega a su radical inversión. Al llevar al extremo el platonismo, invirtiéndolo, Nietzsche agota las últimas posibilidades del pensar platónico-metafísico y en él llega la modernidad a su consumación. Heidegger adivina en la colocación nietzscheana del devenir en el cobijo del eterno retorno el ocultamiento del resentimiento propio de la metafísica, un resentimiento extremadamente espiritualizado que tiene que recurrir, precisamente, a la metafísica del eterno retorno para justificar el devenir54.

Es la crítica filosófica a la metafísica la que le permite a E. Jüngel abrir el espacio de la fe cristiana. El pensamiento metafísico anclado en categorías griegas no puede pensar conjuntamente a Dios y la caducidad. La premisa de todo pensar metafísico sería la valoración negativa de la caducidad y precisamente contra esta desacreditación de lo perecedero y lo caduco hablaría la palabra de la cruz. En la cruz no se declara la inocuidad de lo caduco, sino la insuperable seriedad de la muerte, el sufrimiento y las angustias humanas. El pensar metafísico no puede pensar la muerte real de Dios. Este prejuicio metafísico es una de las salidas de la metafísica hacia el ateísmo. El otro camino hacia el ateísmo sería el que se abre con Nietzsche y es que éste, aún pretendiendo negar el prejuicio metafísico clásico, no puede soportar la caducidad del "Dios en la cruz" y reelabora una metafísica de la vida. Nietzsche se opuso vehementemente a la posibilidad de pensar conjuntamente a Dios y a la caducidad, de la manera como lo hace la confesión cristiana, no porque asuma el prejuicio metafísico clásico, sino porque no puede pensar un Dios sufriente, carente de poder. Nietzsche puede pensar un Dios caduco, pero no un Dios débil, que se asusta y llora ante la muerte.

Nietzsche habría sido uno de los pocos filósofos en darse cuenta de la novedad del Dios de Pablo y de percibir la posibilidad de un Dios que se concibiera desde la unidad con la caducidad. El Dios crucificado haría posible pensar a Dios de otra manera que mediante una mezcla de esencia suprema (concebida metafísicamente) y moral pequeño-burguesa. "Dios pensado como el haber llegado a liberarse de la moral, oprimiendo en sí toda la abundancia de los contrarios vitales y salvándolos y justificándolos en tormento divino. Entonces, la

54. M. Heidegger, “QQuién es el Zaratustra de Nietzsche?”, Conferencias y artículos, Barcelona, 1994, p. 107 ss. El conocido libro de E. Fink, La filosofía de Nietzsche, 1969, sigue en lo fundamental la lectura de Heidegger, pp. 198-201. 
muerte del Dios concebido metafísicamente anunciada por Nietzsche sería solamente la superación del 'Dios moral': 'Sí, en el fondo, lo único superado es el Dios moral"'55, y Dios sería de nuevo pensable "como el más allá, lo másarriba-de la moral mezquina de los holgazanes del bien y mal" 56 . Nietzsche barrunta aquí que en el mensaje cristiano de la cruz podría haber algo totalmente distinto al "nihilismo" de la moral cristiana, que tanto le repugnaba.

Nietzsche reconoció muy bien y con mucha agudeza que con Pablo se inicia una nueva compresión de Dios. Es muy posible que lo haya visto más claramente Nietzsche que muchos cristianos. Pero lo que no soporta Nietzsche es la característica de que Dios, en medio de la caducidad, no sólo haya de ser pensado como Dios, sino incluso como un Dios sufriente que grita, se angustia y llora. El Dios crucificado no sólo justifica la caducidad, sino también la debilidad, la neurosis, la carencia de poder, el sufrimiento, la decrepitud, la exposición a la muerte, y es justamente esta impotencia y debilidad la que no soporta la metafísica nietzscheana. En la nueva metafísica nietzscheana, la divinidad (Dionisos) es el símbolo de la fuerza y la potencia de lo perecedero. El sí a la vida y a la tierra de Nietzsche es todavía un sí condicional. Por tanto, no puede más que afirmar del Dios crucificado que es la negación de Dios.

Según Jüngel, Nietzsche es uno de los filósofos que más agudamente ha captado la incompatibilidad del modo cristiano de entender a Dios con la idea metafísica de Dios. Pero Pablo celebra la idea de un Dios crucificado no con melancolía, sino que la piensa como evangelio, como algo agradable y regocijante. ¿Qué hay de regocijante en la impotencia del crucificado? La impotencia del crucificado es para Pablo el modo en el que se cumple la potencia-vital de Dios57. La impotencia no es entendida como contradicción con la potencia de Dios, y solamente hay un fenómeno humano en el que potencia e impotencia no se contradicen, en el que más bien la potencia se cumple como impotencia. Ese fenómeno es el acontecimiento del amor. Así como Heidegger siente en su ateísmo que la filosofía puede llegar a ser más poderosa que una bomba atómica58, el cristiano experimenta de algún modo la risible verdad de que la impo-

55. E. Jüngel, Dios como misterio del mundo, Salamanca, 1984, p. 249.

56. Ibid., p. 250.

57. 2 Cor 13,4 .

58. M. Heidegger se preguntaba después del holocausto nazi si el camino del pensar en la sencillez y el silencio de su decir podía aportar ya alguna cosa, y contesta, con una extraña confianza en la humanidad en medio de tanto horror, que aquellos que sigan cste camino "permancccrán. Algún día podrán, con la suave violencia del camino del campo, resistir a la gigantesca fuerza de la energía atómica que el cálculo humano ha proyectado y construido como una cadena para sus propios actos". M. Heidegger, "El camino del campo", traducido por F. Pino Canales en Diálogo Filosófico 8, Mayo-Agosto 1987, p. 137. 
tente fuerza del amor puede llegar a ser más fuerte que la muerte. El poder del amor es la unidad de potencia e impotencia, y como tal lo más radicalmente opuesto a la voluntad de poder, que se escandaliza ante la debilidad y la impotencia. Por consiguiente, el Dios crucificado es no sólo la negación más perfecta del Dios de la metafísica, sino también de la nueva metafísica nietzscheana, que diviniza sólo los aspectos vigorosos y atractivos de la vida.

Lo apasionante de la crítica de Jüngel a Nietzsche es que puede tomarse la crítica de éste totalmente en serio y, por así decirlo, meterle un gol en su propio terreno. Probablemente sólo un teólogo podía apreciar en toda su hondura el drama religioso de Nietzsche y que Dionisos es más metafísico que el crucificado. La pregunta que se hace Jüngel es por qué Nietzsche, que ha apreciado toda la novedad del Dios paulino frente al Dios de la metafísica, no la hace valer como inicio de una comprensión de Dios totalmente distinta, nueva, que hubiera sido apropiadísima "para alabanza y justificación de todo lo perecedero"59. El motivo de esa cerrazón ante la verdad cristiana estaría en que Nietzsche quería que fuese alabado y justificado el pasar de lo perecedero sólo en cuanto libre de debilidad y sufrimiento60. Por eso, y en ese punto concreto, Nietzsche, aunque va contra la metafísica, permanece prisionero de ella. En su polémica contra el Dios crucificado ha pensado la caducidad de la vida de un modo abstracto, al querer ver justificada la vida perecedera sólo en la cima de su vitalidad61.

A. González ha insistido aquí en que la filosofía de X. Zubiri sería quizás más apta para desprenderse de presupuestos filosóficos que aun en la acerada crítica de Jüngel están presentes y lo llevan a pensar las realidades positivas del dolor, del sufrimiento y de la muerte con el concepto griego de negatividad. En Jüngel, pensar a Dios en la cruz implica asumir la negatividad en el seno de la divinidad, y el único modo que tiene de pensarlo es con categorías existenciales y no reales 62 . Uno de los problemas de pensar "existencialmente" el Dios.en la cruz es que inmediatamente nos aleja de las dimensiones sociales y políticas de ésta, de los pueblos y de las mayorías crucificadas del mundo63.

59. Jüngel, op. cit., p. 246.

60. Ibid., p. 246.

61. Ibid., p. 247.

62. Es un tema que supera las posibilidades de este artículo, pero que está esbozado en A. González, “Aproximación a la filosofía de la religión de Xavier Zubiri”, Realidad 63, mayo-junio, UCA, San Salvador, pp. 293-306, en A. González, La novedad teológica de la filosofía de Zubiri, Fundación Zubiri, p. 35 y más detalladamente en Trinidad y liberación, San Salvador, 1995. Este tipo de prejuicios puede llevarnos fácilmente a una comprensión de la encarnación donde Dios propiamente no está en la cruz física y realmente y donde la revelación es antes un mensaje y una palabra que una forma de vida.

63. Las tcologías existencialistas suclen permanecer cicgas ante las dimensiones de ia Cruz que legítimamente acentúa la teología de la liberación. Véase por ejemplo J. 


\section{A. González: El anticristo como permanencia en el esquema de la ley}

El pecado original y fundamental de la humanidad sería para A. González una estructura de nuestra praxis. Esta estructura es designada como "esquema de la ley". Se trata de una especie de configuración universal de la acción que nos lanza a establecer una correspondencia entre la acción y sus resultados. Toda acción humana busca y espera tener resultados proporcionales a la misma. La universal apertura de la praxis humana nos impone justificarla, y si carecemos de otro camino, nuestra praxis sólo se puede justificar por sus resultados. Dios, la dialéctica, el dinero, la historia, la magia o cualquier otra cosa aparece como el garante, en último término, de la correspondencia. El "ídolo" religioso y secular por excelencia sería la garantía entre la acción y sus resultados, aquí o más allá. Nuestros esfuerzos no serían absolutamente vanos. Desde luego mediatizados por el esquema de la ley, el espíritu de camello en términos nietzscheanos, podemos hacer cosas buenísimas, pero siempre envueltos en la ansiedad de saber si realmente somos "valiosos". De esta configuración de la acción humana no podemos salir por nuestros propios esfuerzos, porque entonces la liberación sería el resultado de nuestras propias acciones y seguiríamos bajo el pecado fundamental de la humanidad. Todos estamos bajo el esquema de la ley, a menos que seamos liberados del mismo.

Es importante subrayar que el "esquema de la ley" al que alude A. Gonzalez no se refiere a la ley en cuanto leyes o códigos rituales religiosos, que tengamos que obedecer. Se trata de algo más primordial que aquella sabiduría humana que descubre que el cumplimiento de la ley mata. De hecho, siempre es posible leer el evangelio como expresión de esta sabiduría humana. Es la apasionante lectura que realiza del mismo F. Hinkelammert: "La ley, si no es interpelada por el sujeto viviente, se transforma en una gran aplanadora contra la vida, en una máquina de matar y en suicidio colectivo de la humanidad. Ese es el pecado que se comete cumpliendo la ley"64. Para Hinkelammert, la sabiduría evangélica consistiría en interpelar la ley y liberarla para la vida humana. La muerte de Jesús revelaría precisamente la maldad rotunda de la ley y nos salvaría al hacer transparente el hecho de que se peca cumpliendo la ley, intentando hacer justicia. El pecado del mundo sería la maldición de la ley y la utopía cristiana, siempre realizada ya y nunca completamente, consistiría en la utopía de quitar este pecado65. Sin embargo, "el esquema de la ley" del que habla A. González es la configuración de la acción que subyace a toda ley, también a la sabiduría

Sobrino, "Lectura de la resurrección de Jesús desde los crucificados del mundo", Sal terrae, 1982.

64. F. Hinkelammert, "El pecado que se comete cumpliendo la ley", El grito del sujeto. Del teatro-mundo del evangelio de Juan al perro-mundo de la globalización, Costa Rica, 1998, pp. 23-38.

65. Ibid., p. 42. 
evangélica que subraya Hinkelammert y a toda sabiduría humana que pretenda por los propios esfuerzos humanos salirse de este esquema.

El "esquema de la ley" no se opone al bien, sino al "esquema de la fe". Bajo el "esquema de la fe" desconfiamos de nuestras obras y aceptamos la gratuidad de la justificación. Tanto bajo el esquema de la ley como bajo el esquema de la fe somos libres para hacer el bien y el mal, pero en ningún caso somos libres para salirnos del esquema de la ley. "Si pensamos en obtener la liberación del esquema de la ley mediante un primer paso nuestro, seguimos todavía sometidos al pecado fundamental de la humanidad"6h. El Dios crucificado sería precisamente la permanente negación de todo "esquema de la ley" y de toda reactualización del mismo.

Enfrentados a la cruz, en los mismos evangelios se presentarían tres posibles configuraciones de la acción humana67. La primera es la asimilación más genuina del esquema de la ley: Jesús es un impostor, el castigo fue justo y el esquema de la ley funciona correctamente en la historia. Es la lógica de los fariseos. La segunda posibilidad, crítica con el esquema de la ley más genuino, no deja de ser una recaída en este mismo esquema, en la medida en que todo depende de los esfuerzos y de la sabiduría humana. Es la lógica pagana encarnada por Pilato. Jesús es un buen hombre, un hombre libre, incluso podría decirse de él que encarna la plenitud de lo humano, pero Dios no interviene en la historia o simplemente el Dios-amor no existe fuera de los corazones humanos. La radical alteridad de Dios y de su gracia no es más que un deseo. El amor sería exclusivamente una verdad humana. Autores como Feuerbach y Nietzsche pueden muy genéricamente enmarcarse aquí. Siempre cabe la sospecha de que, efectivamente, el Dios crucificado no sea más que una proyección del amor humano. De nada sirve argumentar como Barth y decir que en la religión el hombre parte de la busca hacia Dios y en la fe cristiana es Dios quien ha venido a buscar al hombre, pues es muy fácil darle la vuelta al argumento y decir que esta solución es la manera más sutil que tiene el hombre de proyectar a Dios. Se imagina que Dios viene al encuentro68. La única respuesta intelectualmente honesta creo que es la que apunta $\mathrm{H}$. Küng: la sospecha permanece siempre como sospecha, pero de la sospecha no se sigue que, efectivamente, el Dios-amor, el Dios crucificado, sea una proyección humana. Es más, también cabe sospechar de la fe en la naturaleza humana de Feuerbach. La tercera posibilidad es la del esquema de la fe. Dios mismo estaba en la cruz, Dios mismo ha sufrido la maldición de la ley.

66. A. E. Sánchez, “La crítica de Nietzsche al cristianismo: crítica al esquema de la ley".

67. A. González "Dios y la realidad del mal”, Del sentido a la realidad, Madrid, 1995, pp. 214-219.

68. Eusebi Colomer, "Nietzsche y el cristianismo", El pensamiento alemán de Kant a Heidegger, op. cit, p. 111. 
"Si Dios hubiera intervenido, Jesús hubiera sido justificado, pero todas las demás víctimas de la historia hubieran sido condenadas, pues aparentemente no se merecían la intervención de Dios. Si Dios muere en la cruz, se afirma su radical solidaridad con todos los pobres de la tierra. Pero al mismo tiempo se afirma que Dios no castiga a los malos. La cruz es por esto una oferta de reconciliación universal"69.

Nuestra liberación es, entonces, un regalo que no tiene ningún otro fundamento que el amor gratuito de Dios. Si nos liberáramos nosotros mismos, lo que ha sido gratuito ya no sería gratuito. La crítica de A. González a Nietzsche es, en un primer momento, muy parecida a la de Jüngel: "En realidad, desde el cristianismo podemos reprocharle a Nietzsche el hecho de que no se atreviera a amar esta vida hasta sus últimas consecuencias: como si él mismo no se atreviera a amar esta vida tanto en sus alegrías como en sus miserias, es decir, en cuanto en ésta aparece el fracaso y la derrota, en fin, la muerte en cruz"70. El cristianismo sería un sí incondicional a la vida, incluso en el fracaso, en el sinsentido, en el llanto, en la miseria, en la enfermedad y en la muerte. La vida es amada en todos sus aspectos sin la abstracción de la metafísica invertida a la que la somete Nietzsche, con la misma ternura con que Jesús acarició a la hemorroisa, pidió agua, lloró desconsolado etc. Lo novedoso es que en la perspectiva de A. González, Nietzsche no escapa del esquema de la ley o mejor, si se quiere, su crítica del cristianismo al esquema de la ley es más radical y va más allá que la crítica de Nietzsche a este esquema. En la cruz se rompe la proporcionalidad entre la acción y sus resultados, dando paso a la gratuidad, al esquema de la fe, que es el único antídoto contra el esquema de la ley. En la fe nos encontramos con el único esquema de acción capaz de superar efectivamente todo resentimiento.

Sin embargo, a pesar de la grandeza de esta visión, no dejamos de caer en una extraña aporía. La pregunta inmediata es cómo Dios puede ser tan retorcido para lanzarnos universalmente a una configuración de la acción bajo el esquema de la ley de la que sólo él mismo puede librarnos. Si no queremos caer en ningún género de maniqueísmo o de dualismo, otorgándole algún tipo de entidad ontológica al mal, no basta que respondamos diciendo que el esquema de la ley depende del ser humano que ha utilizado su libertad, no para agradecer, sino para hacerse a sí mismo y que Dios respeta la libertad humana. Afirmar esto implica pensar que el esquema de la ley depende, en alguna medida, de nuestros actos. Si nosotros somos los que hemos adoptado el esquema de la ley para relacionarnos con Dios y con las cosas, también somos, de alguna manera, libres para salir del mismo.

69. A. González, "Dios y la rcalidad del mal", Del sentido a la realidad, p. 217.

70. A. Sánchez, "La crítica de Nietzsche al cristianismo: crítica al esquema de la ley", op. cit., p. 94. 
Ahora bien, si la salvación depende, en algún grado, de nosotros, en el planteamiento de A. González no saldríamos del esquema de la ley y si queremos salir de él tenemos que recurrir al Espíritu Santo, a que Dios transforme internamente nuestra praxis. Si bajo el esquema de la ley nuestra praxis es guiada por nuestro propio espíritu, en el esquema de la fe, es guiada por el Espíritu Santo. ¿Pero no existe al menos la decisión de confiar y de dejar trabajar al Espíritu Santo? ¿Cae esta decisión también bajo el esquema de la ley? ¿Hay que decir que todo pende del Espíritu Santo? Podrá decirse que la libertad cristiana solamente es posible por la obra del Espíritu Santo en nosotros, ¿pero no implica al menos la libertad cristiana una libertad humana anterior, que es la decisión de abrimos a la gracia? Si respondemos afirmativamente, parece que estamos de nuevo en el esquema de la ley. No sirve aquí cl expediente de recurrir a la identificación de la gracia con la libertad cristiana, porque una de dos: o los agraciados están predestinados a ella o de ellos depende en algún grado el dejar actuar al Espíritu Santo. Ciertamente, si se acentúa en demasía la libertad humana desaparece la gracia, pero si se afirma absolutamente la gracia parece que se resiente en algún grado la libertad humana.

\section{E. Drewermann: el anticristo como esclavitud psicológica}

El libro Clérigos es probablemente uno de los pocos en la literatura católica donde la sexualidad es tratada con una extraordinaria finura y respeto, y sobre todo, con sinceridad y honestidad sin restarle un ápice de su complejidad: "La manera más elocuente e inequívoca de medir el grado de madurez psicológica de un clérigo consiste en observar cómo se comporta con el sexo opuesto. El miedo, la crispación, la seguridad ficticia, la actitud huidiza, la profesionalización de las relaciones humanas o, al revés, la cordialidad, la franqueza, la receptividad, la sensibilidad por los demás, son las más fidedignas señas de identidad del corazón humano"71. Toda la letanía de los miedos y angustias sexuales es cuidadosamente desmenuzada por Drewermann 72. Después de un serio análisis de los tabúes sexuales que se suelen sostener en ambientes eclesiásticos, en lo referente a la masturbación, la homosexualidad, la atracción por el sexo opuesto, etc., a lo que Drewermann nos invita es a enfrentar los problemas, sabiendo que ningún problema humano admite probablemente una solución definitiva.

Su crítica al sacerdocio, quizás por conocimiento de causa, es más radical que la de Nietzsche: "Se trata, más bien, de pálidos criminales, según la descrip-

71. E. Drewcrmann, Clérigos, Madrid, 1995, p. 486.

72. El drama de la relación de los sacerdotes con mujeres socialmente inhibidas, donde el sacerdotc cs el único hombre que cntra en su vida y la dificultad de ćste para reconocer una búsqueda angustiada y encima ayudarla implicando su propia persona, cs descrito con especial delicadeza por E. Drewermann, op. cit., p. 778. 
ción de Nietzsche, hombres que pecan por debilidad, no por bravura, y que, corroídos por sus escrúpulos de conciencia, ponen toda su pasión en sufrir y hacer sufrir, en vez de irradiar alegría y felicidad"73. E. Drewermann aprecia en el anticristo de Nietzsche la mejor denuncia contra la conversión de la neurosis en santidad, la enfermedad en elección y la angustia vital en confianza en la providencia divina ${ }^{74}$, y reclama, junto a la libertad del pensar, una auténtica libertad del sentir: "hay algunos para quienes la virtud es un espasmo bajo un látigo"75.

Como cristianos -insiste Drewermann-, ante el compromiso con los demás o con determinadas clases sociales, deberíamos preguntarnos qué significa esto para la propia vida del sujeto que decide asumirlos, cómo cuadran con su carácter, sus aspiraciones personales. La crítica de Drewermann a los intentos de imponer categóricamente un compromiso es que, para tomar en consideración el monstruoso cúmulo de miseria que nos rodea en el mundo, hay que atreverse a mirar y levantar las cercas del sufrimiento que nos corroe dentro. Los que se toman la libertad de "realizarse personalmente no son gente que se retira, sino personas que se exponen, quizás por primera vez en su vida, y que actúan decididamente sobre esa parcela de sufrimiento humano que tiene en ellas mismas su concretización más sangrante"76.

"La exégesis de la Biblia, la teología moral, la reflexión dogmática no deberían seguir pasando como de puntillas por el sufrimiento psíquico del hombre. Porque lo que es hoy, en vez de empezar por hacerse uno mismo más humano, se confía en la asombrosa creencia de poder salvar a la humanidad, en abstracto; en vez de intentar una seria transformación de la Iglesia, anclada en unas estructuras que se muestran tan inhumanas, lo que pretende el teólogo, con su ilusión de cambiar la sociedad, es granjearse el aprecio y un mayor reconocimiento por parte de los suyos. [...] Por eso es imprescindible reconocer que, en determinadas circunstancias, todos los discursos sobre la libertad, el humanismo, el amor etc., no garantizan en absoluto que la persona que los profiere, no sea un perfecto inmaduro, lleno de servidumbres, totalmente egoísta, inclinado a las más feroces vejaciones y que sólo pretende aplastar a los demás con sus ideas -tal vez aprovechables-, porque sólo demostrando su virtuosismo podrá rescatar el caparazón de su propio 'yo', convertido en intelectualismo barato, de la ciénaga de todos sus latentes complejos de inferioridad" 77.

73. Ibid., p. 486.

74. Ibid., p. 501 .

75. Ibid., p. 525.

76. Ibid., p. 598.

77. Ibid., p. 600. 
E. Drewermann considera que el psicoanálisis puede enseñar a la práctica pastoral de la Iglesia una forma de castidad abierta y realmente liberadora78: la delicadeza y la ternura en el trato con los demás, la verdadera humildad como un aprender a convivir con las propias ambigüedades, sin necesidad de hacerse valer ni de demostrar nada; la obediencia como escucha de la palabra del otro y de las más íntimas inclinaciones sin otro objetivo que erradicar el sufrimiento; la liberación de la crispación del poder y de la afirmación de uno mismo de modo que no seamos los únicos en disfrutar de la vida, sino que sean muchos los que puedan tener una vida en paz; la felicidad y el amor concreto como el poder que nos permite enfrentarnos con absoluta libertad contra todos los poderes, las personas o las estructuras que destruyen la vida. Drewermann acaba su libro con la proclama de Nietzsche contra la divinización del Estado y de la Iglesia. Paradójicamente, encontramos en aquel, que en el tópico común es acusado de nazi, uno de los mejores alegatos de la filosofía contra el poder: "¡Todos quieren llegar al trono! Su locura consiste en creer que la felicidad radica en el trono. Y, con frecuencia, el fango se asienta en el trono, y también el trono se asienta en el fango. Hermanos míos, ¿es que queréis ahogaros con el aliento de sus hocicos y sus concupiscencias? ¡Mejor harías rompiendo las ventanas y saltando al aire libre! Aún está la tierra a disposición de las almas grandes. Todavía quedan muchos puestos vacantes para eremitas solitarios o en pareja, puestos saturados del perfume de mares silenciosos. Todavía queda abierta, ante las almas grandes, la posibilidad de una vida libre. En verdad, quien menos posee, tanto menos es poseído. ¡Alabada sea la pequeña pobreza! Donde el Estado acaba, allí comienza el hombre que no es superfluo; allí comienza la canción de quienes son necesarios, la melodía única e insustituible"79.

Drewermann, sin duda un profundo conocedor de la terrible miseria psíquica que puede llegar a experimentarse dentro y fuera de ambientes eclesiásticos, acentuará el combate contra la miseria psicológica por encima de toda otra miseria, una lectura existencial del evangelio por encima de una proyección política y una lectura terapéutica por encima de una escatológica. Bien recibidas sean las exageraciones, si con ello se consigue visualizar toda la gravedad de la miseria y del sufrimiento que es capaz de anidar no sólo en ambientes eclesiásticos, sino en el corazón de los seres humanos. Pero de ello no se sigue que "lo esencial no es liberar al hombre de la injusticia política, de la pobreza social" y que "la liberación esencial del cristianismo es liberarlo de la angustia y del miedo" 80 . Drewermann, tan refinado en la exploración de los entresijos del alma, parece absolutamente ingenuo a la hora de valorar los entresijos sociales.

78. Ibid., p. 655.

79. F. Nietzsche, Así habló Zaratustra, Madrid, 1978, pp. 82-86.

80. Ibid., p. 602. 


\section{El anticristo como absolutización de una liberación parcial}

El reconocimiento del crucificado como Dios es la antítesis de todo Dios metafísico y trasmundano y al mismo tiempo de todo endiosamiento humano y de toda reducción del cristianismo a un humanismo. Si se quiere, es un humanismo tan radical que es sobrehumano. En palabras de L. Boff: "Así de humano sólo puede serlo el mismo Dios"81. El cristianismo es una oferta gratuita de liberación radical. Nos libera incluso del esfuerzo de liberación, de la dicotomía entre el "esquema de la ley" y el "esquema de la fe" y del dilema entre libertad y gracia. El punto de partida de la fe cristiana es, indudablemente, la gracia, pero una gracia que, como el amor entre los amantes, no hace más que potenciar la libertad. Dios da el primer paso y nos ama, independientemente, de todo lo que hagamos. Y del mismo modo que, mientras vivamos, la ambigüedad histórica es indesterrable, siempre parece que permanece en nosotros un ramalazo del esquema de la ley. Cuanto menos, de nosotros depende dejarnos amar. Ante Dios, todos somos hijos pródigos. El cristianismo no es así la guinda de todos nuestros esfuerzos liberadores. Al contrario, porque nos sabemos libres de toda cuenta, de toda medida y de toda búsqueda de éxitos y resultados, el cristiano puede permanecer libre de toda nomenclatura eclesiástica y no eclesiástica, de toda esclavitud psicológica y de toda recaída en una metafísica y en un esquema de la ley. Lograr unir toda la madeja de las liberaciones humanas y pensar el cristianismo como una oferta de liberación radical 82 es el permanente reto de la teología de la liberación83. Que la liberación cristiana no es sólo una liberación interior, espiritual o existencial, sino que tiene dimensiones globales y sociales es lo que enfatizará la teología de la liberación, y de ese énfasis difícilmente se

81. Citado por J. I. González Faus, El factor cristiano, Madrid, 1994, p. 25. A mi modo de ver este libro constituye una apasionante reivindicación y revisión de la teología de la liberación.

82. La libcración radical es más que una libcración integral. Un no cristiano pucde aspirar a una liberación integral (liberación de las cadenas estructurales y sociales y liberación de las cadenas interiores), pero no puede aspirar a la liberación de todo pecado, de toda ley y de toda muerte. Eso no quiere decir que, de hecho, no haya muchos no cristianos mucho más libres quc los cristianos. Tampoco quiere decir que no tengamos que conquistar día a día una liberación integral. Sin embargo, "el sobrehombre" cristiano, "el hombre nuevo", no es el hombre del futuro ni un ideal histórico, sino la humanidad de Dios, el Dios crucificado.

83. Un bello ejemplo de este esfucrzo teológico lo encontramos en el libro sencillo, pero hondo y delicioso, de G. Fourez, Una buena noticia liberadora. Evangelio para un mundo en crisis, Santander, 1984. También Nictzsche es para Fourez el principal introductor a la fe cristiana. Así empieza su bello libro: "El espíritu fue primero camcllo; más tarde, cl camello se hizo león, por último el león se convirtió en un niño." "Si no cambian y os hacen como los niños, no entrarán en el reino de Dios" (Mt 18, 3). 
llegará a abusar tanto como del énfasis espiritualizante. Ciertamente, Dios nos ama, y en el reino de Dios no se mide sino que se da gratuitamente, pero su amor nos alcanza gracias al amor de las personas que nos lo hacen concreto y manifiesto, y ello nos justifica, es decir, nos dispensa de demostrar que somos buenos y nos permite ser auténticos. Pero muy vano sería este amor si no tuviera repercusiones estructurales y sociales. En este sentido, creo que la teología de la liberación se muestra más apta para integrar todo el cúmulo de las liberaciones humanas y es menos sospechosa de servir a intereses "extraños" que muchas otras teologías.

Ahora que ya no tenemos ninguna dialéctica que nos asegure que los pobres van a triunfar y que difícilmente podemos considerar la fe cristiana como la guinda de una metafísica de la historia; ahora que se han liquidado las garantías metafísicas ilustradas, que en teología solían significar la consideración del reino de Dios como algo a lo que nos vamos acercando históricamente, en una especie de proceso asintótico; ahora que el pobre y marginado no cuenta con la bendición de ningún realismo político, que tiene todos los números para la rifa del fracaso, y que parece absurdo, fuera de la lógica del mundo, el compromiso con ellos, ¿no aparece con mas realce el dogma ${ }^{84}$ central de la teología de la liberación y del cristianismo: el amor preferencial de Dios por los pobres, no porque éstos sean mejores, tengan más méritos, sean los sujetos de la historia, sino simplemente porque son los malditos de la ley, la siempre nueva presencia escandalosa del Dios crucificado? ¿Cómo se podrá seguir diciendo ahora frente a las comunidades de religiosos y religiosas, comunidades de base, grupos, trabajadores y profesionales anónimos en barrios y comunidades campesinas, muchas veces fuera de toda esperanza racional, que la teología de la liberación es, en su núcleo, un afán de resultados o un realismo político? Dios se muestra en la cruz al lado de los aparentemente "abandonados de Dios" y no de los aparentemente benditos por él. ¿Qué puede escapar más a todo cálculo fariseo que el amor (cuando éste es real y concreto) ${ }^{85}$ a los pobres, a las "clases peligrosas"

84. Es hermosa, en este sentido, la carta de Jon Sobrino a I. Ellacuría: "Eras discípulo fiel de Zubiri, filósofo y tcólogo de la libcración, teórico de movimientos políticos populares, pero no peleabas por esas teorías como si fuesen un dogma. Más bien cambiabas tus puntos de vista - tú, inflexiblc - y cuando lo hacías una sola cosa era la que te hacia cambiar: la tragedia de los pobres. Por eso pienso, que si algún dogma inamovible tuvistc, éstc fuc sólo uno: cl dolor de los pucblos crucificados". Carta de Jon Sobrino a Ignacio Ellacuría, noviembre de 1990, citado por Teresa Whitficld, Pagando el precio, San Salvador, 1998.

85. "En la vida, hay mucha gente dispuesta a 'ayudar'. Pero hay pocas personas dispuestas a querer... La rclación de ayuda es una rclación que domina cl que la presta (puedo ayudar hasta donde quiera). Mientras que la relación de cariño es una relación en la que no se sabe hasta dónde pucde llevar. A Jesús, de hecho, lo llevó hasta la muerte". José M. Castillo, "Jesús el pueblo y la teología", Revista Latinoamericana de Teología" agosto, 1998, 44, p. 137. 
lejos de la agradable y buena gente de la clase media? ¿Qué puede revelar mejor la gratuidad del reino? ¿No cobra la teología de la liberación una radicalidad inusitada y no puede integrar en la centralidad del pobre todas las otras miserias y pobrezas humanas? La opción preferencial por los pobres puede estar repleta de complejos, resentimientos, ansias de santidad y de martirio (tal vez menos que en otras opciones preferenciales), pero $\iota^{\text {no }}$ es genuinamente esta opción la expresión más radical y menos sospechosa de la gratuidad evangélica? Los pobres y marginados de toda condición (comunidades indígenas, campesinos, barrios marginales, mujeres, enfermos de sida, homosexuales, enfermos mentales, inmigrantes ilegales, delincuentes, okupas, trabajadoras sexuales, etc.) son los malditos de la ley y también de la ley de Dios. ¿No nos lanza el amor del Dios crucificado a construir una sociedad en la que todos y cada uno de los hombres y las mujeres puedan ponerse en pie - re-sucitar- y atreverse a ser ellos mismos? La buena noticia liberadora, la liberación radical cristiana o es también liberación integral, vida en abundancia para todos 86 , o se hace acreedora de todas las críticas que los diferentes humanismos le han planteado. Ciertamente, la liberación cristiana no se agota en la consecución de un sistema económico, político y social más justo ni en la consecución de unas vidas con menos miedos sexuales y menos pesares y sufrimientos psicológicos, sino en la "liberación del pecado, la ley y la muerte"87. Pero si la liberación cristiana no nos libera también histórica, económica y psicológicamente no se ve muy bien qué puede tener de buena noticia, y sobre todo no se palpa la alegría y el júbilo ante tamaño regalo.

La fábula de la metamorfosis del espíritu en león, camello y niño, en Zaratustra, es probablemente una de las mejores fábulas filosóficas de la imposibilidad de una autoliberación radical. No se trata sólo de la imposibilidad de vencer humanamente la ley, el pecado y la muerte, ni de la dificultad de construir un mundo nuevo, sino de eso tan pedestre que en la vida diaria acontece a veces difícilmente: la reconciliación, el amor y la amistad; y en lo que a veces muy poco podemos hacer. Se trata también de la diferencia entre nuestros deseos y nuestros actos, entre lo que realmente hacemos y lo que creemos hacer. El mismo Nietzsche más parece el león que el niño que desearía ser. El rechazo de todo idealismo larvado, la cruda realidad de lo que somos, las luces y las sombras, las grandezas y miserias de todos los seres humanos, lo inmerecido de todo

86. Con muy buen tino, Rolando Alvarado en su tesis sobre "Tcología y salvación en Ignacio Ellacuria" prefiere hablar de "vida en abundancia" para todos los seres humanos que de liberación integral, pues la liberación plena que nos regala el Dios cristiano no depende de nuestros éxitos o fracasos liberacionistas y mucho menos cabe concebirla como culminación o guinda de un proceso histórico o personal, y la liberación integral podría inducir a pensar la libertad cristiana en estos términos, $p$. 182 ss., Madrid, 1997.

87. I. Ellacuría. "Liberación: misión y carisma de la Iglesia latinoamericana" ECA 268 (1971) p. 78.

Digitalizado por Biblioteca "P. Florentino Idoate, S.J."

Universidad Centroamericana José Simeón Cañas 
amor incondicional y la radical humanidad de Jesús es quizás lo que más nos puede acercar al Dios cristiano. Así, Nietzsche roza la experiencia cristiana de Dios.

El espíritu transformado en camello es capaz de grandes sacrificios y de un extraordinario coraje para defender sus ideales, pero permanece esclavo del propio fardo que se ha echado encima: “¿Qué es pesado?, así pregunta el espíritu de carga, y se arrodilla, igual que el camello, y quiere que lo carguen bien. ¿Qué es lo más pesado, héroes? así pregunta el espíritu sufrido para tomarlo sobre sí y alegrarse de su fortaleza. [...] ¿Acaso no es humillarse para hacer daño a la propia soberbia?, ¿hacer brillar la propia tontería para burlarse de la propia sabiduría?. [...] ¿O acaso es amar a quienes nos deprecian? [...] Con todas estas cosas, las más pesadas de todas, carga el espíritu de carga: semejante al camello que corre al desierto con su carga, así corre él a su desierto"88. "Pesadas son para él la tierra y la vida; y así lo quiere el espíritu de pesadez" 89 . El camello cree que para que su existencia sea valiosa tiene que hacer cosas valiosas. La acción se justifica por sus éxitos y resultados. Sin duda cuando los seres humanos viven como camellos son capaces de hacer las cosas más extraordinarias, de soportar lo indecible, de cumplir a rajatabla las órdenes del dueño y de sentir satisfacción del cumplimiento del deber, pero se trata siempre de una satisfacción envuelta en la ansiedad de saber si lo que uno hace es realmente valioso.

Luego el espíritu se convierte en león. "En otro tiempo adoraba el 'Tú debes' como lo más sagrado y ahora tiene que hallar la locura y la arbitrariedad en lo más sagrado, para conquistar la libertad a costa de lo más querido"90. Del "yo debo", el espíritu transformado en camello pasa a veces, en la soledad del desierto, al "yo quiero". Pero el león sigue en la soledad del desierto. Más solo, si cabe, que el camello, porque ya no está ni siquiera acompañado por las justificaciones normales. El león lucha contra el dragón del deber "en cuyas escamas brillan valores milenarios"91. Reacciona contra la ley, pero es incapaz de ser libre y crear. Pero después el espíritu de león carnicero se trasforma en niño. "Sí, hermanos míos, para el juego de la creación se necesita una afirmación santa: el espíritu lucha ahora por su propia voluntad, el que perdió el mundo vuelve a ganarle"92. El espíritu transformado en niño ríe, juega, empieza a ser él mismo, sin necesidad de estar justificándose a sí mismo, legitimándose o en permanente revuelta. Así termina no sólo el primer discurso de Zaratustra, sino también el último. El león echado a los pies de Zaratustra se deja acariciar y se

88. F. Nietzsche, Así habló Zaratustra, Madrid, 1997, pp. 53-54.

89. Ibid., p. 273.

90. Ibid., p. 55.

91. Ibid., p. 54.

92. Ibid., p. 55.

93. Ibid., p. 440. 
echa a reír93. La madurez de Zaratustra se alcanza en esta última transformación. El niño se identifica con el mismo Zaratustra, el maestro que quiere liberar la reflexión filosófica, la metafísica, vigente hasta ahora, del espíritu de venganza. "Que el hombre sea liberado de la venganza: esto para mí es el puente a la más alta esperanza, y un arco iris después de largas inclemencias de tiempo"94. "Mas cosa distinta es, sin duda, lo que las tarántulas quieren. [...] Por eso desgarro vuestra tela para que vuestra rabia os induzca a salir de vuestra caverna de mentiras, y vuestra venganza destaque detrás de vuestra palabra 'justicia'"'95.

¿Cómo consigue Nietzsche esta transformación del espíritu? ¿Cómo consigue liberarse del espíritu de venganza que corroe la reflexión metafísica incapaz de aceptar la realidad en todos sus aspectos? En Nietzsche, el paso del león al niño no tiene garantía, no hay una dialéctica hegeliana, ni ningún progreso que nos asegure la transición. Precisamente, estamos hablando de liberación, no de necesidad. Los mismos textos de Nietzsche más bien revelan en su persona el fracaso de esta metamorfosis. En este espacio de incertidumbre entre el león y el niño arranca la posibilidad de la experiencia cristiana, una experiencia que no tiene ningún privilegio filosófico, ni tan siquiera mayor profundidad humana, que una experiencia atea, agnóstica o panteísta 96 . El cristiano, confrontado ante experiencias profundas de este tipo, no puede más que respetar, sobrecogerse, balbucear y acaso fundirse en un abrazo como el del idiota con el suicida. Reflexionar y pensar siempre nuevamente esta experiencia es la gran tarea del teólogo.

Una experiencia que es "escándalo" para los judíos y "locura" para los griegos97. No se trata de que en el cristianismo no haya ni signos ni sabiduría, sino que hay otro tipo de signos y otro tipo de sabiduría, que aquella que persiguen judíos y griegos ${ }^{98}$. El escándalo de la biografía entera de Jesús, de su vida y de su muerte, es el nuevo signo cristiano frente a cualquier otra señal esperada de mesianismo 99 y la confianza personal 100 , la nueva sabiduría. Si el judío no puede encajar que el mesías muera, el griego no puede tolerar que la sabiduría

94. Ibid., p. 155. Según una nota póstuma del Zaratustra que cita Heidegger, éste culminaría en la siguiente máxima: "Sólo el amor debe juzgar, el amor que se olvida de sí mismo en sus obras”, M. Heidegger, “¿Quićn es el Zaratustra de Nietzsche?, Conferencias y artículos, Barcelona, 1994, p. 105. "Qué singular y qué extraño exclama Heidegger- para la opinión habitual que la gente se ha hecho de la filosofía de Nietzsche", Ibid., p. 99.

95. F. Nietzsche, Así habló Zaratustra, pp. 155-156.

96. X. Zubiri, Hombre y Dios, Madrid, 1984.

97. X. Zubiri, El problema teologal del hombre: cristianismo, Madrid, 1997, p. 46.

98. Ibid., p. 48.

99. Ibid., p. 52.

100. Ibid., p. 53. 
penda de unas confianzas personales, en lugar de la necesidad con que la razón estructura el universo. El griego "no podía admitir que la razón absoluta estuviese pendiente de unos acontecimientos perfectamente contingentes a lo largo de la historia. De ahí que estimara locura la predicación de san Pablo: la locura de sustituir la razón por la historia"101. La locura de la sabiduría cristiana consiste para el griego en ser adhesión personal102, confianza en alguien103. Esta experiencia es la que permite y otorga al espíritu la suficiente confianza como para transformarse en niño y no estar demostrando cosas a los demás, ni a sí mismo. Cuando los actos humanos se configuran a partir de esta experiencia es posible, en algunos casos, que se haga exactamente lo mismo que sin ella, pero las obras dejan de ser obras de la ley. Es una experiencia que no nos fuerza a nada y que tampoco cabe identificar con un deber. Pero sí "constituye ese impulso primario en que un amor, que no se ha merecido, es recibido por aquel que es término de él"104. No se necesita ni decir que se debe ser un niño. Simplemente, cuando se es amado, el "fardo" de la existencia se desvanece, se empieza a jugar y se deja de temer el tomar riesgos en la vida. En la experiencia cristiana, la transformación del espíritu en niño no pende de ninguna metafísica. Es una transformación gratuita, un regalo, algo que a veces ocurre como un milagro. "Es un contento de sí mismo que desborda y que prodiga su abundancia a los hombres y a las cosas"'105. No es una nueva obligación de camello, ni se puede hablar de ello como algo por lo que tenemos que luchar. Esto no dejaría de ser una reedición del espíritu de camello. El niño no es "mejor" que el camello o el león, ésta sería la forma de razonar del camello; lo que ocurre es que el camello se hace león y el león se hace niño. Y por otra parte, el goce y la inocencia son las dos cosas más púdicas: ninguna de las dos puede ser buscada 106.

Pero muchos hemos tenido la oportunidad de conocer personas que viven liberadas del espíritu de pesadez y de venganza, personas que aman más allá del castigo y de la recompensa, más allá del bien y del mal y de todo resentimiento. Apurando la metáfora, podría decirse que por más que en el límite toda persona tenga algo de camello, de león y de niño, hay algunos que parecen gozar de una confianza fundamental que les permite analizar la sociedad y sus propios actos sin demasiada ansiedad. Esta justificación "gratuita", allende toda justificación racional, da a los que la experimentan suficiente confianza para ser capaces de contemplar sus propias ambigüedades sin necesidad de demostrar nada, ni de mantener una imagen de sí mismos que les parezca válida. A pesar de todos los

101. Ibid., p. 53.

102. Ibid., p. 56.

103. Ibid., p. 53.

104. Ibid., p. 80.

105. F. Nietzsche, El etcrno retorno, Argentina, 1974, \&55, p. 75.

106. F. Nictzschc, Así habló Zaratustra, op. cit., \&5, p. 357. 
pesares, de la ambigüedad de los propios actos y de estar formando parte de una sociedad injusta, no necesitan estar permanentemente moralizándose a sí mismos y a los demás. Se sienten y hacen sentir a gusto. Y actúan más por su propio querer que por alguna necesidad inconsciente. La motivación última del cristiano es la loca gratuidad del amor, que constituye - paradójicamente- "la máxima perfección y la mínima obligación"107. Esta liberación de la moral, esa dádiva, sólo es posible a través de la experiencia de ser amados efectivamente, que envuelve a la vida en una amabilidad primordial. En esta experiencia somos justificados gratuitamente y liberados de la maldición de la ley y la lógica de la medida y la retribución, de esa loca pretensión de medirnos por el fruto de nuestras acciones 108 . Esta es la buena noticia, la liberación del evangelio cristiano. Sin una experiencia tangible de este tipo, en el seno mismo de la opresión, de la miseria y de todo género de condiciones sociales, no hay cristianismo posible. Evidentemente, esta acción liberadora no es privativa de los cristianos, a veces se da incluso sin que lo sepan los actores 109 , pero es lo más propio de la experiencia cristiana. El cristianismo no es una religión de justos, sino de agradecidos, de personas que se saben aceptadas, independientemente de todo cuanto hayan podido hacer. La filosofía no puede, ciertamente, llevar a la fe cristiana, pero una filosofía liberadora y crítica con toda suerte de metafísicas puede tal vez acercarnos a sus puertas.

107. J. I. González Faus, El factor cristiano, 1994, p. 49.

108. También en el Bhagavad-Gita, el "evangelio" del budismo, se apunta a esta liberación del "espíritu de pesadcz", de la cficacia y de los frutos de la acción.

109. Quizás aquí adquiera todo su sentido hablar de cristianos anónimos. Aunque como explica muy bien J. I. Gonzálcz Faus, la expresión "cristiano anónimo", acuñada por Rahner, no es una denominación sociológica que pueda ser dicha ni explicada al no cristiano, sino que únicamente sirve para interpelar al interior de la fe. J. I. González Faus, op. cit., p. 117 ss. 